\title{
TRANSPORTATION OPERATIONS FUNCTIONS OF THE FEDERAL WASTE MANAGEMENT SYSTEM*
}

\author{
L. B. Shappert ${ }^{1}$ and M.J. Klimas ${ }^{2}$ \\ lOak Ridge National Laboratory, Oak Ridge, TN, and \\ ${ }^{2} \mathrm{DOE}$ - Chicago Operations Office, Argonne, IL \\ CONF-890631--59 \\ DE89 015041
}

For presentation at the Ninth International Symposium on the Packaging and Transportation of Radioactive Materials (PATRAM) 1989 in Washington, D.C., on June 11-16, 1989.

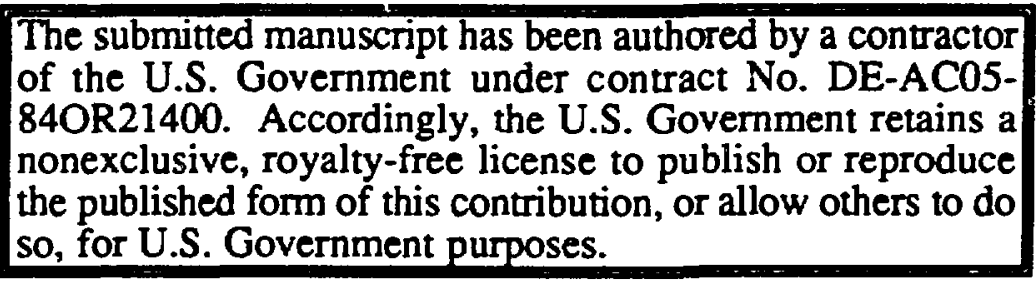

* Research sponsored by the Office of Civilian Radioactive Waste Management, U.S. Department of Energy, under contract DE-AC05-84OR21400 with Martin Marietta Energy Systems, Inc. 


\section{TRANSPORTATION OPERATIONS FUNCTIONS OF THE FEDERAL WASTE MANAGEMENT SYSTEM}

L. B. Shappert ${ }^{1}$ and M.J. Klimas ${ }^{2}$

1Oak Ridge National Laboratory, Oak Ridge, iN and ${ }^{2}$ DOE-Chicago Operations Office, Argonne, II

This report was prepared as an account of work sponsored by an agency of the United States Government. Neither the United States Government nor any agency thereof, nor any of their employees, makes any warranty, express or implied, or assumes any legal liability or responsibility for the accuracy, completeness, or usefulness of any information, apparatus, product, or process disclosed, or represents that its use would not infringe privately owned rights. Reference herein to any specific commercial product, process, or service by trade name, trademark, manufacturer, or otherwise does not necessarily constitute or imply its endorsement, recommendation, or favoring by the United States Government or any agency thereof. The views and opinions of authors expressed herein do not necessarily state or reflect those of the United States Government or any agency thereof. 


\section{INTRODUCTION}

The Federal Waste Management Transportation System, developed for the U.S. Department of Energy's Office of Civilian Radioactive Waste Management (DOE/OCRWM) will interface with over 100 utility-owned reactors, a waste repository, possibly a Monitored Retrievable Storage (MRS) facility, and other support facilities; it will also (under normal operating conditions) be responsible for the shipment of over 3000 metric tons of uranium (MTU) throughout the U.S. This work will encompass a highly complex transportation operation, far exceeding any spent fuel shipping program implemented to date. To ensure that the system is adequately specified and all of its functions are identified, a Systems Engineering approach is being applied to develop the transportation system. This work was approved as part of the DOE/OCRWM program through the Chicago Operations Office, and the work is being carried out by the Transportation Operations Project Office (TOPO).

The transport system will consist of a number of elements, including facilities, equipment, personnel, services, and operation procedures. Transportation operations will have to manage these elements to ensure that multiple-site campaigning can be carried out on a continuous basis for a 40-year period, even though the specific sites, equipment requirements, and payloads will vary significantly, both across sites and across time, as the system evolves. Current efforts must ensure that the system elements are appropriate, integrated, and proven; that the needs of the waste generators are accommodated; and that the receipt rate and fuel requirements at the Federal Waste Management System (FWMS) facilities are constantly matched with the transport capabilities.

This paper documents the functions that are necessary to operate the OCRWM transportation system. OCRWM's mission is to accept and transport spent fuel and highlevel waste from waste generators to FWMS facilities. The emphasis is on transportation operations and assumes that all necessary facilities are in place and equipment designs and specifications are available to permit the system to operate properly. The information reported in this paper was developed for TOPO (Shappert et al., 1988) and is compatible with the draft revision of the Waste Management System Requirements and Description (SRD) (1986). 
In order to completely identify the functions, it was necessary to identify the interfaces between functions, including those external to the transport system. Effort has been made to avoid overspecifying these external functions because fully defined interfaces with the MRS, geologic repository, waste generators, and other entities are yet to be developed.

The identification of these functions is the first step in a systems engineering process that reflects the OCRWM Mission Plan (1985) and will result in the development of a transportation system that is built, tested, and ready for operation. One of the next steps will be to allocate these functions, a process that will determine where, how, and by whom they are to be performed.

The three primary transportation-related functions identified in the OCRWM Waste Management SRD (1986) are (1) accept the waste, (2) transport the waste, and (3) provide associated support functions. Each of these functions has been broken down into appropriate lower-level subfunctions.

\section{ACCEPT FUNCTION}

The functions and related activities developed in this section are confined to to those that directly support DOE in its acceptance of fuel and wastes at a waste generator site. They are largely drawn from, and are interpreted from, information in the generic utility contract (10 CFR 961.11, 1988).

According to the generic utility contract, DOE will accept waste from a waste generator in a cask or package ready for shipment. Therefore, for DOE, the accept function includes taking custody of and title to the spent fuel and waste and obtaining the appropriate backup documentation. Associated with this is a waste accountability function, the scope of which is yet to be defined.

Because the waste is received in a cask ready for shipment, activities within the accept function consist of (1) observing certain operations at waste generator sites (some of which could precede final loading and shipping activities by many months), (2) verifying data in documentation provided on a shipping lot and obtaining additional documentation if needed, and (3) determining overall readiness of a cask and payload for acceptance and transportation. This implies a need for a continuing exchange of information between waste generators and DOE. "Observe and verify" activities within this function assist in ensuring that waste offered to DOE is consistent with prior agreements and that the shipment is ready for transportation. Title to the material passes to DOE upon completion of these custody transfer activities.

DOE may determine that most of these functions may be reduced to audit activities if, over time, it is determined that the data provided by waste generators is accurate and complete. The generic utility contract leaves this decision largely to DOE's discretion.

\section{TRANSPORT FUNCTIONS}

Transport functions begin at the point where DOE has taken custody of the waste and has obtained a waste generator off-site shipment record and certification of readiness of shipment for transport. The functions end with delivery and tumover of the waste at a 
FWMS facility. All surface modes of transport are assumed to be available; intermodal transfers are also assumed to be available where appropriate.

The primary transport functions are as follows:

2. Transport waste from waste generator
2.1 Perform preshipment activities (truck, rail, or barge),
2.2 Perform traffic management activities,
2.3 Provide waste carriage, and
2.4 Perform delivery.

Preshipment functions represent those steps that are taken between the time a transpor cask, on its vehicle, is transferred to OCRWM from the waste generator and the time the cask is transferred to a carrier for shipment. These activities are designed to verify carrier personnel and equipment readiness; provide instructions to carriers; ensure proper shipping documentation and package certification; and determine that cask temperatures, radiation levels, and contamination levels are within regulatory limits. This function ends with the release and dispatch of the shipment. Throughout this activity, the role of the UCRWM representative is mainly one of coordination and administration.

The traffic management activities involve dispatching administrative activities and performing dispatch operations. The administrarive activities include scheduling both loaded and unloaded shipments, obtaining appropriate permits, coordinating the acquisition of equipment, and maintaining status and performance records. Dispatch operations provide the point of contact into the uransportation operations system for all routine (and most unplanned) activities for the individuals that perform the hauling and in-vehicle communications, as well as the physical security tasks.

The shipping modes of highway, rail, and barge differ from each other in that several casks will probably be moved on a single train or barge, whereas each truck will carry only one cask. This difference places an accumulation function within the rail and barge activities. Most other aspects of preshipment activities are similar and independent of the method of transport.

The delivery function provides the interface with the repository and/or the MRS, depending on the facilities available. Activities within this function will be relatively independent of the facility to which the delivery is made.

\section{SUPPORT FUNCTIONS}

Numerous support activities must be provided for by the transportation support system to enable the "accept" and "transport" functions to be carried out. These functions will be performed by trained personnel using computer hardware and software, casks and related equipment, facility resources, and combinations of these. The functions identified herein are independent of any organizational structure and are intended to guide the development of the support system description and related operating plans. Seventeen support functions have been identified and are shown below. The first six are operational in nature, whereas the last eleven tend to be administrative.

3. Support functions

3.1 Traffic planning, 


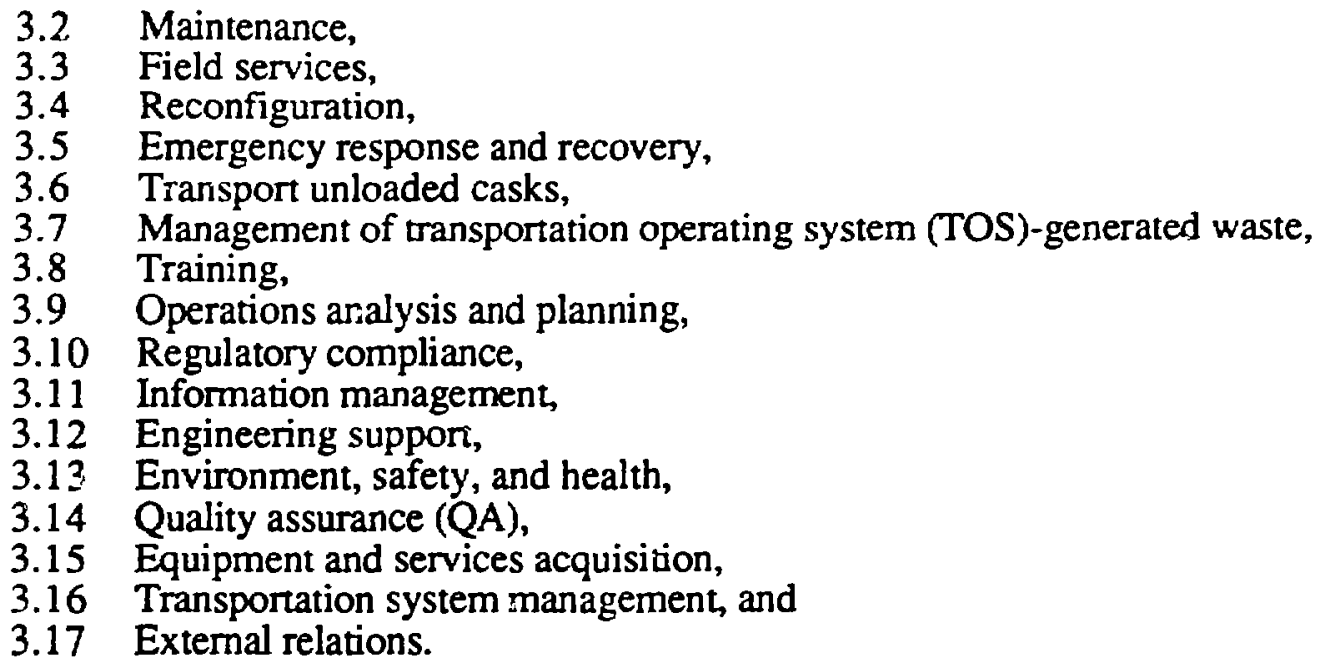

A few of the support functions are described in more detail below.

Traffic planning functions include both campaign and route planning and are essential to ensure that waste transportation resources are applied effectively. Activities in this function will be to develop, assembie, and distribute campaign planning information to the operations management organizations at FWMS receiving facilities and to the affected waste generator facilities. In addition, planning information will be distributed to the TOS organizations responsible for field service, traffic management, maintenance, and others whose work schedules will be directly affected by the campaign planning activities. This information will cover the deployment status not only of casks and vehicles, but also of ancillary equipment, reconfiguration components (cask baskets), and maintenance and field service resources. An important part of this planning function involves coordinating transportation operations schedules with the waste generators and the repository or MRS receiving facilities.

Maintenance functions include planning, routine maintenance, off-normal maintenance, repair, and modification. An important factor in the smooth operation and minimum disruption of the transportation system is the ability to plan and schedule maintenance operations properly. This, in turn, depends on gathering data on casks, vehicles, and ancillary equipment from the time they are introduced into the system. As each piece is received, its maintenance "clock" must start and its maintenance history be tracked throughout the life of the equipment. Most maintenance will probably be performed at a specialized facility, but incidental maintenance may be performed elsewhere (such as at a waste generator site or a rail and truck repair facility).

Field services provide the technical support functions that are required by the transportations system to sustain the transportation operations (1) at shipment origin facilities, (2) during transit in the public domain, and (3) at receiving or destination facilities. This includes providing technical advice and assistance to support normal, routine operations as well as to cope with abnormal events. These functions may be advisory in nature, consist solely of observations and appropriate information transfer, or involve activities that might be required by cask or vehicle maintenance during transport. Additional functions include inspecting equipment needed for cask handling at a specific site, confirming compatibility between equipment and waste generator facilities, providing 
technical advice during loading and unloading operations, and training site personnel. It is expected that field service functions will be minimal at DOE facilities.

From time to time, some casks may require reconfiguring (i.e., the changing of cask internals) in order to accept the next scheduled waste type. This function can vary from changing inserts in spent fuel baskets to allow for the shipment cf different length fuel to a complete basket changeout to permit the movement of a different type of waste (e.g., canistered fuel). The reconfiguration function may occur at the waste generator facility, repository, MRS, or cask maintenance facility, depending on the scope of the reconfiguration requirements and logistical considerations.

Emergency and response functions consist of those that are performed as part of routine operations that establish and maintain emergency response and recovery (ERR) capability, as well as the accident response and recovery functions that take place when an incident occurs. This subdivision is consistent with DOE Order 5500.1A and with the current DOE Emergency Management System structure and organizational plans. The normal activities include maintenance of plans, procedures, and data bases that allow the incident/accident response functions to be initiated quickly and efficiently as soon as a request for help is received. The incident/accident ERR function includes execution of previously prepared plans and procedures, providing qualified technical personnel to fulfill requested support activities, and aiding in the recovery of transport system equipment. It is important to point out that any activities carried out by the operating system will always be coordinated with the Emergency Management System personnel at Department of Energy Headquarters (DOE/HQ) and the appropriate DOE field office.

The movement of unloaded casks through the system has been addressed as a separate support activity here. The casks are referred to as unloaded rather than empty because an internally contaminated cask without fuel assemblies may not be considered empty according to Department of Transportation (DOT) definitions. In addition to the repository, the sources of these unloaded casks could be the Cask Maintenance Facility, newly purchased casks, or other facilities at which repair or maintenance operations have been carried out.

Training activities are an integral part of transportation support functions and will allow system acceptance and transport activities to be accomplished in a safe, efficient manner and in compliance with applicable statutes, regulations, and DOE orders. Although this training will be primarily for staff members operating the transportation system, provisions for training operations personnel at waste generator sites and receiving facilities will be developed as needed.

Operations analysis and planning functions will include assessing current transportation activities, performing long-range planning, and identifying and evaluating alternatives. The evaluation of activities will include monitoring, analyzing, and providing transportation system feedback with regard to performance, cost, and schedule parameters as specified in the Transportation Business Plan (1986). Examples of items to be tracked include (1) incident/accident rates; (2) cask system equipment availability and utilization factors; (3) compatibility with utility handling facilities; (4) radiation exposure histories; (5) transporter servicing, maintenance, and repair costs; (6) transportation operation costs; (7) recurring problems and delays; and (8) compliance with training, inspection, and shipping schedules. Analysis of collected data will be utilized to maintain or improve system safety and efficiency. 
The operation of the transportation system will necessitate the execution of an information management function that involves the development and maintenance of an extensive body of data. The data will provide input for (1) planning and licensing activities; (2) developing facilities, equipment, services, and interfaces; and (3) reporting of trends and other activities. Examples of the information to be stored inciude certificate of compliance data, licensing data, as-built cask and facility drawings, state requirements data, federal and state legislative data, shipping records, maintenance and repair records, accountability records, health physics records, and QA records.

It is assumed that complete specifications for approved cask systems are available prior to startup of the waste management transportation system and that the cask prototypes and major required facilities have been approved, designed, sited, licensed, and constructed. Nevertheless, engineering support functions for the TOS will be required and will involve design, analysis, and other engineering operations to support ongoing licensing, regulatory, and equipment acquisition activities. These functions will also provide engineering support to the field service or maintenance organizations as requested. Since much of the engineering activities will have been completed by the time the transportation system is operating, this is not expected to be a large effort.

In addition to the cask and vehicle fleet, it is expected that there will be a wide variety of specialized equipment, tools, spare or repair parts, and services that will have to be procured during the time the TOS is in operation. This will give rise to an equipment and services acquisition function that will involve both purchasing and contracting activities. The effort will be responsive to traffic planning, maintenance, field services, and engineering support functions.

Because of the high visibility and sensitivity of the transport of radioactive materials throughout the U.S., there will need to be an activity whose function is to support the FWMS interactions with all public and private organizations that are interested in matters that could impact the operating transportation system. This is identified as an external relations function and it will involve support to DOE in the areas of external relations and information services.

There are a series of other administrative-type functions that will be required to keep the system operating properly and efficiently. The most important of these include transportation system management, $\mathrm{QA}$, licensing, and regulatory compliance activities. As the system matures, additional functions will become more important. For example, system enhancement projects will explore cost-effective and safety-related improvements to the system. TOS facilities that discharge wastes will require a system waste management function. Health, safety, and environmental activities will emphasize radiation and industrial safety, as well as protection of the environment.

\section{CONCLUSIONS}

In keeping with the systems engineering process, this paper identifies the functions that are necessary to support the OCRWM Mission Plan (1985) and to maintain an efficient and safe operating transport system. These functions will aid in identifying important issues and trade-off studies that will help shape the final system. It is expected that they will also be used to initiate allocation of the functional responsibilities to various parts of the OCRWM system. 


\section{REFERENCES}

10 CFR 961.11, "Standard Contract for Disposal of Spent Nuclear Fuel and/or High-level Radioactive Waste" (1988).

Mission Plan for the Civilian Waste Management Program, Vol. I of III, Office of Civilian Radioactive Waste Management (OCRWM), DOE/RW-0005, Washington, DC (1985).

Shappert, L. B. et al., Transportation Operations Functions of the Federal Waste Management System, ORNL/TM-10811 (ORO/TOP-5403.0), Martin Marietta Energy Systems, Oak Ridge National Laboratory (June 1988).

Transportation Business Plan, OCRWM, DOE/RW-0046, Washington, DC (Jan. 1986).

Waste Management Systems Requirements and Descriptions (SRD), OCRWM, DOE/RW0063 (Jan. 1986). 